\title{
On the Relevance of Earnings Components in Valuation and Forecasting
}

\author{
Pengguo Wang \\ Xfi Centre for Finance and Investment \\ Exeter University Business School \\ Exeter EX4 4ST \\ UK \\ Email: p.wang@exeter.ac.uk
}

December 2013 


\title{
On the Relevance of Earnings Components in Valuation and Forecasting
}

\begin{abstract}
This paper articulates the links between relevance of an earnings component in forecasting (abnormal) earnings and its relevance in valuation in a nonlinear framework. The analysis shows that forecasting relevance does not imply valuation relevance even though valuation irrelevance is implied by forecasting irrelevance. Firstly, I consider an accounting information system where earnings components "add up" to a fully informative earnings number. Secondly, I analyze two accounting systems where a "core" earnings component is the relevant earnings construct for valuation and the second earnings component is irrelevant but may be predictable and relevant in forecasting other accounting items. I find that dividend displacement effect on earnings and the dynamics of individual earnings components are critical in this analysis.
\end{abstract}

Keywords: valuation, forecasting, earnings components, residual income valuation model

JEL: G17, G32, M41 


\section{Introduction}

Financial analysts and empirical financial accounting researchers often focus on the valuation relevance and forecasting ability of earnings components. Perhaps surprisingly, theoretical equity valuation models provide only limited guidance on the appropriate specification of tests of informational relevance of earnings components. A valuation irrelevant accounting variable can be forecasting relevant to the expected future earnings. Dividends are examples of such a variable in the Miller and Modigliani (1961) framework. Dividends paid affect future earnings expectations through the dividend displacement effect - dividends reduce book equity from which future earnings are generated. However, a valuation irrelevant earnings component can be also forecasting irrelevant if it is unpredictable (Ohlson 1999). A legitimate question is that under what conditions a forecasting relevant earnings component is also valuation relevant.

It has long been recognized that equity value is a nonlinear function of accounting and non-accounting numbers. Burgstahler and Dichev (1997) document a nonlinear relation between equity market value and net income, a result they attribute to the effects of an adaptation option applicable to lower levels of profitability. A firm's ability to adapt its investment opportunity set to alternative uses represents a potentially valuable option that will be reflected in the market value of its equity (see, for example, Lee and Lee 2010). Consistent with economic intuition that capital follows profitability, Biddle et al. (2001) develop model and show convex relations between future and current (abnormal) earnings, and between unrecorded goodwill (market value added) and current abnormal earnings. Zhang (2000) considers the 
effects of contingent investments on the properties of the valuation function where firms have both growth and adaptation options. ${ }^{1}$ A nonlinear valuation model necessarily leads to a nonlinear earnings information dynamic in a no-arbitrage economy. However, existing literature does not address the relevance of earnings components in valuation and forecasting of future earnings in a more general nonlinear setting. ${ }^{2}$ In this paper, I analyze the relationship between informational relevance of an earnings component in valuation and forecasting starting from an equity valuation model that incorporates real operating options such as investment growth options and abandonment options.

The residual income valuation model (RIVM) establishes a fundamental link between valuation and forecasting, the object of forecasting being abnormal earnings. An earnings component is defined in Ohlson (1999) as irrelevant if it may be combined with another accounting item, or dropped from the information set, without loss of information for forecasting subsequent period abnormal earnings (forecasting irrelevance) or for valuation (valuation irrelevance). Under a specified linear accounting system, it is shown

\footnotetext{
${ }^{1}$ Other studies also document related non-linearities include Barth et al (1998), Berger et al. (1996), and Subramanyam and Wild (1996).

${ }^{2}$ Although prior literature challenges the empirical validity of the Ohlson (1995) model, it focuses on linear abnormal earnings information dynamics and corresponding linear valuation model. For example, Callen and Morel (2001) find that the extension of AR(1) to $\operatorname{AR}(2)$ process of abnormal earnings does not explain severe underestimation of market prices. Tsay et al. (2008) implement Ohlson (1995) model with 'other information' incorporating abnormal earnings information itself in a linear fashion. Higgins (2011) attempts to adjust for serial correlation in the residual income valuation model and improve the accuracy of forecasts of stock prices.
} 
that when an earnings component can be netted off with dividends any two of the following three imply the third: (i) unpredictability; (ii) forecasting irrelevance to next period abnormal earnings; (iii) valuation irrelevance. By introducing a distinction between "core" and "transitory" earnings, which is defined to be unpredictable and irrelevant in forecasting abnormal earnings, the transitory component is consequently irrelevant in valuation and core (abnormal) earnings is the only earnings component necessary for valuation. Similarly, Feltham and Ohlson (1995) justify the disaggregation of earnings and book value into financial and operating components, based on the assumed lack of predictability of abnormal earnings from financial activities. Likewise, other analysis of the valuation-forecasting link in the context of earnings components has so far been limited to valuation irrelevant earnings components in a linear information framework (Stark 1997). ${ }^{3}$ My analysis is similar in the spirit of Pope and Wang (2005) who analyze the valuation and forecasting links of earnings components in a linear framework. However, I extend this line of research to a more general nonlinear setting in which (i) a valuation irrelevant earnings component may forecast other accounting items and may itself be predictable; (ii) a forecasting relevant earnings component is also valuation relevant.

I show in a general setup that a valuation irrelevant earnings component is not necessarily irrelevant in forecasting future abnormal earnings outcomes although forecasting irrelevance of an earnings component implies valuation

\footnotetext{
${ }^{3}$ Stark (1997) shows that an earnings component is irrelevant in linear valuation if it has no predictive ability for other accounting items. Ohlson (1999) presents a linear model where a "transitory" earnings component is irrelevant in valuation if it is irrelevant in forecasting abnormal earnings and if it is, itself, unpredictable.
} 
irrelevance. I emphasize on informational relevance of an earnings component in forecasting in all future period abnormal earnings as indicated in the residual income valuation model. Assuming the clean surplus accounting and no arbitrage condition, my analysis suggests the importance of dividend displacement effect on value and on earnings when discussing informational relevance of an earnings component. Dividend displacement effect is characterized by whether the marginal effect of dividends on the expected subsequent period earnings is equal to (negative) cost of equity capital, and whether there exists an one-for-one trade-off between current dividends and market value. Dixit and Pindyck (1994) and Ashton et al. (2004) argue that a firm's real (adaptation) value will in general be affected by its dividend policy. If dividend displacement effect does not holds due to reasons such as changes in investment opportunity set or conservative accounting, an earnings component via dividend policy may be forecasting relevant to the expected future earnings even if it is valuation irrelevant. If both dividend displacement effects hold, I show that earnings components being aggregated in valuation implies, and is implied by earnings components being aggregated in forecasting all future expected abnormal earnings under some plausible conditions. When both dividend displacement effects hold and dividends have no effect on an earnings component, I find that the predictability of the earnings component to itself is critical to determine the forecasting relevance if it is valuation irrelevant. Collectively, my analysis is built on two steps. Firstly, I explore the implication of dividend displacement. Secondly, I pay attentions on the role of the earnings component on dividend policy.

This paper differs from the relevant literature in a number of ways. First, 
unlike Pope and Wang (2005) who extend Ohlson $(1995,1999)$ by examining the role of accounting conservatism on valuation and forecasting, ${ }^{4}$ my analysis is motivated by the existence of a nonlinear relation between equity market value and accounting observables due to real growth and adaptation options. The role of an earnings component in a linear information system is clearly different from that in a nonlinear system. Second, while earnings components may be co-dependent, I show that interdependence between earnings components in a nonlinear setup under dirty surplus accounting can be much more complicated than that documented in Pope and Wang (1995). The trade-off between two earnings components may depend on core abnormal earnings. Third, while Pope and Wang (2005) investigate dirty surplus accounting, where earnings component is combined with contemporaneous dividends without information loss in valuation and forecasting, I recast it in a nonlinear setup and examine an additional kind of dirty surplus accounting, where earnings component has prior period adjustment. Fourth, to my knowledge, this is the first to apply the 'chain rule' on uncertain accounting numbers in accounting based equity valuation research.

The results have potential implications for the design and specification of empirical tests of informational relevance of 'other comprehensive income items' under SFAS 130/IAS 1 and unrealized gains/losses of derivative instruments under FAS 133/IAS 39, as well as prior period earnings adjustments including reclassification of gains/losses in cash flow hedging.

The remainder of the paper is organized as follows: in Section 1 I de-

\footnotetext{
${ }^{4}$ They argue that conservatism acts as an adjustment to the book value anchor in the abnormal earnings-based equity valuation.
} 
fine informational (ir)relevance in forecasting and valuation; In Section 2 I present my analysis of the links between valuation irrelevance and forecasting irrelevance in a general model setup; In Section 3 I discuss the implications of the analysis and conclude the paper.

\section{Assumptions and Definitions of Informa- tional Relevance}

My model setup follows Ohlson (1999). I assume that the set of accounting items in period $t$ financial statements comprises $\left\{x_{1 t}, x_{2 t}, d_{t}, b_{t}\right\}$, where $x_{1 t}$ and $x_{2 t}$ are two earnings components in period $t$ summing to aggregate earnings (or comprehensive income), $x_{t}\left(\equiv x_{1 t}+x_{2 t}\right) ; d_{t}$ is dividends paid (net of new equity contributions) in period $t$; and $b_{t}$ is equity book value at $t$. The evolution of accounting information follows a Markovian process. I denote earnings component $x_{1}$ as "core earnings" when I analyze "dirty" surplus earnings.

I make the following three basic assumptions:

A1. The firm is valued in a risk-neutral, arbitrage-free market. This implies that $E_{t}\left[P_{t+1}+d_{t+1}\right]=R P_{t}$, where $P_{t}$ is the value of the firm at the end of period $t$ and $R$ equals one plus the risk-free interest rate. $E_{t}$ denotes expectations based on all available information at time $t$.

A2 The clean surplus accounting relation holds (CSR):

$$
b_{t}=b_{t-1}+x_{1 t}+x_{2 t}-d_{t}
$$


where $b_{t}$ is book value at the end of period $t$. Similar to Ohlson (1995), I also introduce three mathematical restrictions on CSR originating in the accounting for owners' equity: (i) $\partial b_{t} / \partial d_{t}=-1$; (ii) $\partial x_{1 t} / \partial d_{t}=0$; and (iii) $\partial x_{2 t} / \partial d_{t}=0$. Restriction (i) indicates that dividend payments reduce closing book value dollar-for-dollar, while restrictions (ii) and (iii) indicate that components of earnings are independent of contemporaneous dividend payments.

A3. Dividends reduce contemporaneous market value one-for-one, $\partial P_{t} / \partial d_{t}=$ -1 . I refer to this as the dividend displacement effect on valuation. This is consistent with Miller and Modigliani (1961).

In Ohlson (1995) and subsequent analysis (Ohlson 1999; Ohlson and Juettner-Nauroth 2005; Ohlson and Gao 2006), the marginal effect of dividends on the expected subsequent period earnings is assumed or implied to be equal to (negative) cost of equity capital, $\partial E_{t}\left[x_{\tau+1}\right] / \partial d_{\tau}=-(R-1)$ for any $\tau \geq t$. I refer to this as dividend displacement effect on earnings.

Given dividends here are net new capital contribution, dividend displacement effect on earnings also means that the marginal contribution per dollar of new capital to next period expected accounting earnings is equal to the cost of equity capital. I will show that dividend displacement effect has a paramount role in analyzing the informational relevance of earnings components in valuation and forecasting. I start my analysis with the following observations.

Observation 1. Assume A1, A2 and A3. Dividend displacement effect on earnings implies (i). $\frac{\partial E_{\tau}\left[x_{\tau+1}^{a}\right]}{\partial d_{\tau}}=0$ for any $\tau \geq t$, i.e. dividends do not affect future abnormal earnings, where $x_{\tau+1}^{a} \equiv x_{\tau+1}-(R-1) b_{\tau}$ is period 
$\tau$ abnormal earnings or residual income; (ii) Dividends have no effect on unrecorded subsequent period goodwill, i.e., $\frac{\partial E_{\tau}\left[P_{\tau+1}-b_{\tau+1}\right]}{\partial d_{\tau}}=0$.

The first part of the observation is based on the concepts of abnormal earnings, dividend displacement effect on earnings and A2. The second part of the observation is an application of the residual income valuation model (RIVM). It is well-known from Edwards and Bell (1961), Peasnell (1982) and Ohlson $(1989,1995)$ that the RIVM follows directly from A1 and A2:

$$
P_{t}=b_{t}+\sum_{\tau=1}^{\infty} R^{-\tau} E_{t}\left[x_{t+\tau}^{a}\right] .
$$

It follows that abnormal earnings can be written as $E_{\tau}\left[x_{\tau+1}^{a}\right]=R\left(P_{\tau}-\right.$ $\left.b_{\tau}\right)-E_{\tau}\left[P_{\tau+1}-b_{\tau+1}\right]$, abnormal growth of accounting goodwill. Hence we have that $\frac{\partial E_{\tau}\left[x_{\tau+1}^{a}\right]}{\partial d_{\tau}}=\frac{\partial E_{\tau}\left[P_{\tau+1}-b_{\tau+1}\right]}{\partial d_{\tau}}=0$, for any $\tau \geq t$, i.e. dividends have no effect on unrecorded subsequent period goodwill.

Accounting goodwill results from conservatism in accounting for assets in place from past transactions and from the value of unrecognized assets. The observation effectively says that the expected market value of unrecognized assets is independent of dividend paid. This is reasonable and is in the spirit of Modigliani and Miller (1961). There is no reason to expect that dividends paid will result in impairment of assets in place or affect the market value of unrecognized assets for a perceived investment policy and investment opportunity set.

If we define expected economic earnings as $E_{\tau}\left[P_{\tau+1}+d_{\tau+1}-P_{\tau}\right]$, then we have the following observation.

Observation 2. Assume A1, A2 and A3. If dividend displacement effect on earnings holds, then the marginal effects of dividends on the (subsequent 
period) expected economic earnings is equal to the expected accounting earnings, i.e., $\frac{\partial E_{\tau}\left[P_{\tau+1}+d_{\tau+1}-P_{\tau}\right]}{\partial d_{\tau}}=-(R-1)=\frac{\partial E_{\tau}\left[x_{\tau+1}\right]}{\partial d_{\tau}}=\frac{\partial E_{\tau}\left[b_{\tau+1}+d_{\tau+1}-b_{\tau}\right]}{\partial d_{\tau}}$.

The first and second equalities follow A1, A3 and the concept of dividend displacement effect on earnings. The last equality is applying the clean surplus accounting identity (A2). Note that dividends here are dividends net of new capital contributions. Observation 2 implies that the expected marginal accounting rate of return and the marginal economic rate of return on new investment are equal to the cost of equity, i.e., $\frac{\partial E_{\tau}\left[b_{\tau+1}+d_{\tau+1}\right]}{\partial d_{\tau}}=\frac{\partial E_{\tau}\left[P_{\tau+1}+d_{\tau+1}\right]}{\partial d_{\tau}}=$ $-R$ for any $\tau \geq t$.

Following Ohlson (1999), I define earnings component $x_{2 t}$ as informationally irrelevant if it can be combined with another accounting item without loss of information. There are three potentially interesting cases of informational irrelevance in which $x_{2 t}$ is combined with, respectively, $x_{1 t}, d_{t}$ and $b_{t-1}$ in a manner consistent with the CSR assumption A2. Firstly, my analysis is concerned with aggregation of earnings components into comprehensive (clean surplus) earnings, equivalent to the irrelevance combination $\left(x_{1 t}+x_{2 t}\right)$. The case of earnings components aggregation is pertinent for considering questions such as whether operating cash flows and accruals 'add up' to a fully informative earnings number for valuation (forecasting), or conversely whether operating cash flows and accruals are separately useful for valuation (forecasting) (Barth et al. 1999, 2005).

Secondly, I consider the two "dirty surplus accounting" combinations $\left(d_{t}-x_{2 t}\right)$ and $\left(b_{t-1}+x_{2 t}\right)$. If the accounting system reports core earnings, $x_{1 t}$, as the "headline" earnings construct in the income statement, accounting may be described as "dirty surplus". When the dirty surplus earnings 
component, $x_{2 t}$, is valuation (forecasting) irrelevant, separate knowledge of "core" earnings, $x_{1 t}$, alone is required for valuation (forecasting) and $x_{2 t}$ may be combined with, respectively, $d_{t}$ or $b_{t-1}$ without information loss for valuation (forecasting). These cases are pertinent to considering the relevance of transitory earnings components and prior period adjustments, respectively. ${ }^{5}$

Specifically, I am interested in the relevance of an earnings component for valuation and for forecasting future (abnormal) earnings in each of following three information sets $I_{j}(j=1,2,3)$ when compared to the primitive information set, $I_{0 t}=\left\{x_{1 t}, x_{2 t}, b_{t}, d_{t}\right\}:^{6}$

$$
\begin{aligned}
& I_{1 t}=\left\{x_{1 t}+x_{2 t}, b_{t}, d_{t}\right\}=\left\{x_{t}^{a}, b_{t}, d_{t}\right\}, \\
& I_{2 t}=\left\{x_{1 t}, b_{t}, d_{t}-x_{2 t}\right\}=\left\{x_{1 t}^{a}, b_{t}, d_{t}-x_{2 t}\right\}, \text { where } x_{1 t}^{a}=x_{1 t}-(R-1) b_{t-1} . \\
& I_{3 t}=\left\{x_{1 t}, b_{t}, d_{t}\right\}=\left\{x_{1 t}^{a}, b_{t}, d_{t}\right\}, \text { where } x_{1 t}^{a}=x_{1 t}-(R-1)\left(b_{t-1}+x_{2 t}\right) .
\end{aligned}
$$

I define earnings components as informationally irrelevant in forecasting if $E\left[x_{\tau}^{a} \mid I_{1 t}\right]=E\left[x_{\tau}^{a} \mid I_{0 t}\right]$ for all $\tau>t$, and denote this form of forecasting irrelevance FI-1. If $E\left[x_{\tau}^{a} \mid I_{2 t}\right]=E\left[x_{\tau}^{a} \mid I_{0 t}\right]$ for all $\tau>t$, I refer to this form of forecasting irrelevance as FI-2. If $E\left[x_{\tau}^{a} \mid I_{3 t}\right]=E\left[x_{\tau}^{a} \mid I_{0 t}\right]$ for all $\tau>t$, I call this form of forecasting irrelevance FI-3. Correspondingly, in the aggregation case, earnings components are informationally irrelevant in valuation when

\footnotetext{
${ }^{5}$ Many contemporary policy debates surround the relevance of accounting items, including the treatment of unrealized gains and losses on marketable securities and financial instruments, changes in the cumulative foreign currency translation adjustment, and changes in the values of pension liabilities and assets (Dhaliwal et al. 1999; Chambers et al. 2007; Schipper 2007; Bamber et al. 2010).

${ }^{6}$ Following the approach of Ohlson $(1995,1999)$, I could allow for an additional variable reflecting "other information" at time t that is not captured by the current accounting variables. As long as it is contemporaneously uncorrelated with the other variables included in the model, our main results would be unaffected.
} 
$P\left(x_{1 t}+x_{2 t}, b_{t}, d_{t}\right)=P\left(x_{1 t}, x_{2 t}, b_{t}, d_{t}\right)$. I label this case of valuation irrelevance VI-1. If $P\left(x_{1 t}, b_{t}, d_{t}-x_{2 t}\right)=P\left(x_{1 t}, x_{2 t}, b_{t}, d_{t}\right)$, I refer to this form of valuation irrelevance as VI-2. If $P\left(x_{1 t}, b_{t}, d_{t}\right)=P\left(x_{1 t}, x_{2 t}, b_{t}, d_{t}\right)$, I call this form of valuation irrelevance VI-3.

I evaluate the informational relevance of earnings components for both valuation and forecasting future abnormal earnings from the striking link in RIVM, which immediately leads to the following observation.

Observation 3. Assume A1 and A2. If an accounting item is irrelevant in forecasting abnormal earnings realizations then it is also irrelevant in valuation in corresponding type. Specifically, FI-1/FI-2/FI-3 imply respectively VI-1/VI-2/VI-3.

In other words, if an earnings component is valuation relevant (in the sense of VI- $j$ failure), then it must be forecasting relevant (in the sense of FI- $j$ failure) $(j=1,2,3)$. However, the converse is not necessarily true. Valuation irrelevance generally imposes weaker restrictions on the information dynamics than forecasting irrelevance, such that an earnings component can be irrelevant in valuation but still play a role in forecasting (abnormal) earnings.

When $\partial E_{t}\left[x_{t+1}^{a}\right] / \partial d_{t} \neq 0$, the above analysis indicates that $\partial E_{t}\left[x_{t+1}\right] / \partial d_{t}>$ $(<)-(R-1)$ represents a marginal opportunity loss (gain) or a lower (higher) marginal reinvestment return on retained earnings in economic terms. Biased accounting may understate (overstate) expected earnings, such that $\partial E_{t}\left[x_{t+1}\right] / \partial d_{t} \neq-(R-1)$ (Pope and Wang 2005). When dividend displacement effect on earnings does not hold, an earnings component may be forecasting relevant if future dividends depend on this earnings component, 
e.g. $\partial E_{t}\left[d_{t+1}\right] / \partial x_{2 t} \neq 0$. As a consequence $x_{2 t}$ is relevant for forecasting future abnormal earnings even if $x_{2 t}$ is valuation irrelevant. My main interest here is to examine when a forecasting relevant earnings component is also valuation relevant or equivalently a valuation irrelevant earnings component is also forecasting irrelevant.

\section{Informational (Ir)relevance of Earnings Com- ponents in Valuation and Forecasting}

In order to establish associations between the value of equity and currently observable accounting numbers, prior studies have often assumed a linear abnormal earnings dynamics and have then derived closed-form linear valuation expressions. $^{7}$ In contrast, I adopt a similar approach to Pope and Wang (2005), who assume a linear valuation model and then examine the implications for the abnormal earnings dynamics and other model properties. However, unlike Pope and Wang, my valuation model is a nonlinear function of accounting observables. Specifically, I start from a general valuation model with one earnings component in the form of $\mathrm{VI}-j(j=1,2,3)$ and then identify the implied information dynamics for abnormal earnings in my model setup. Based on the information dynamics I further identify conditions that lead to the forecasting irrelevance FI- $j(j=1-3)$ of the earnings component. I discuss each form of informational relevance in turn next.

\footnotetext{
${ }^{7}$ For example, Ohlson (1995), Feltham and Ohlson (1995, 1996), Dechow et al (1999), Barth et al $(1999,2005)$ all start from linear abnormal earnings information dynamics.
} 


\subsection{When earnings components are aggregated}

The centrality of abnormal earnings expectations in valuation based on RIVM suggests that the relation between future abnormal earnings expectations and current information is important in analyzing informational relevance issues. Denote $G \equiv P_{t}-b_{t}$, where $G$ is a real deterministic function defined in $I_{0}$ and continuously differentiable.

When earnings components aggregate in valuation (VI-1), Yee (2000) shows that the general valuation model under A1, A2 and A3 can be written as: ${ }^{8}$

$$
P_{t}=b_{t}+G\left(x_{t}^{a}, b_{t}+d_{t}\right),
$$

where $G(0,0)=0$. It is reasonable to assume $G_{1}^{\prime}>0$, the first partial derivative of $G$ with respect to abnormal earnings is positive - in words, market value of equity is a positive function of abnormal earnings (Ohlson 1995).

From A1, A2 and equation (2), the abnormal earnings process must satisfy the following information dynamics to be consistent with VI-1 valuation irrelevance:

$$
E_{\tau}\left[x_{\tau+1}^{a}\right]+E_{\tau}\left[G\left(x_{\tau+1}^{a}, R b_{\tau}+x_{\tau+1}^{a}\right)\right]=R G\left(x_{\tau}^{a}, b_{\tau}+d_{\tau}\right) .
$$

I first explore the implications of dividend displacement for abnormal earnings dynamics, since an earnings component may be forecasting relevant

\footnotetext{
${ }^{8}$ By assuming A1, A2 and A3, Yee (2000) shows that book value $b_{t}$ and dividend $d_{t}$ must add in valuation of unrecorded goodwill. When 'other information' takes into account, we can rewrite valuation $P_{t}=b_{t}+G\left(x_{t}^{a}, b_{t}+d_{t}\right)+\vartheta_{t}$ and the abnormal earnings dynamics as $E_{\tau}\left[x_{\tau+1}^{a}\right]+E_{\tau}\left[G\left(x_{\tau+1}^{a}, R b_{\tau}+x_{\tau+1}^{a}\right)\right]=R G\left(x_{\tau}^{a}, b_{\tau}+d_{\tau}\right)+R \vartheta_{\tau}-E_{\tau}\left[\vartheta_{\tau+1}\right]$.
} 
for abnormal earnings via dividend policy if dividend displacement on earnings is violated. I then analyze the dependence of future abnormal earnings on the earnings component, conditional on earnings components aggregating, i.e. $\partial E\left[x_{\tau}^{a} \mid I_{1 t}\right] / \partial x_{2 t}$ for any $\tau>t$. For the tractability of my analysis and without loss of generality, I assume that any higher moments of abnormal earnings are independent of any accounting variables. I also assume the solution to equation (2) exists and conditions for the 'chain rule' apply throughout the paper.

Denote $G_{2}^{\prime}$ partial derivative of $G(.,$.$) with respect to the second variable.$ We can show that dividend displacement on earnings implies

$$
E\left[G_{2}^{(n)}(., .)\right]=0, \text { for } n=1,2, \ldots
$$

where $G_{2}^{(n)}$ is the $\mathrm{n}^{\text {th }}$-order partial derivative with respect to the second variable. See the appendix for the proof. Therefore, given $G(0,0)=0$ and equation (3), Taylor expansion gives:

$$
\begin{aligned}
& E_{t}\left[x_{t+1}^{a}\right]+G_{1}^{\prime}(0,0)\left(E_{t}\left[x_{t+1}^{a}\right]-R x_{t}^{a}\right) \\
& +\frac{1}{2} G_{1}^{\prime \prime}(0,0)\left(\left(E_{t}\left[x_{t+1}^{a}\right]\right)^{2}+\operatorname{var}\left(x_{t+1}^{a}\right)-R\left(x_{t}^{a}\right)^{2}\right)+\ldots \\
= & 0
\end{aligned}
$$

where $G_{1}^{(n)}$ is the $\mathrm{n}^{\text {th }}$-order partial derivative with respect to the first variable and $\operatorname{var}\left(x_{t+1}^{a}\right)$ is the variance of $x_{t+1}^{a}$. Hence, in the aggregation case, when VI-1 and dividend displacement on earnings hold, then $E_{t}\left[x_{t+1}^{a}\right]$ in equation (3) can be in general expressed in terms of $x_{t}^{a}$, as can $E_{t}\left[x_{\tau}^{a}\right]$ for $\tau>t+1$ by recursion. Note that the variance and higher moments of $x_{t+1}^{a}$ are independent of $d_{t}$ and $x_{2 t}$ by assumption. Consequently, $\partial E\left[x_{\tau}^{a} \mid I_{1 t}\right] / \partial x_{2 t}=0$ for 
any $\tau>t$, i.e., $x_{2 t}$ is FI-1 forecasting irrelevant. In other words, a forecasting relevant earnings component must be valuation relevant. Moreover, the corresponding valuation model from equations (2) and (4) is:

$$
P_{t}=b_{t}+G_{1}^{\prime}(0,0) x_{t}^{a}+\frac{1}{2} G_{1}^{\prime \prime}(0,0)\left(x_{t}^{a}\right)^{2}+\ldots
$$

Therefore, together with Observation 3 above, dividend displacement on earnings implies that valuation relevance of an earnings component is equivalent to forecasting relevance of the earnings component.

To make a link to prior literature, I consider the following quadratic model:

$G\left(x_{t}^{a}, b_{t}+d_{t}\right)=\alpha_{1} x_{t}^{a}+\alpha_{2}\left(b_{t}+d_{t}\right)+\alpha_{3}\left(x_{t}^{a}\right)^{2}=\left(\alpha_{1}+\alpha_{2}+\alpha_{3} x_{t}^{a}\right) x_{t}^{a}+\alpha_{2} R b_{t-1}$, where $\alpha_{1}$ and $\alpha_{3} \geq 0$. It describes a scenario that the persistence of abnormal earnings depends on current period profitability. This is more realistic than a linear valuation model. Pope and Wang (2005) is a case with $\alpha_{3}=0$, while Ohlson (1995) is a special case with $\alpha_{2}=\alpha_{3}=0$. The no-arbitrage condition and the clean surplus accounting together imply the following abnormal earnings dynamic:

$E\left[x_{t+1}^{a}\right]+\left(\alpha_{1}+\alpha_{2}\right)\left(E\left[x_{t+1}^{a}\right]-R x_{t}^{a}\right)+\alpha_{2} R\left(b_{t}-R b_{t-1}\right)+\alpha_{3}\left(E\left[\left(x_{t+1}^{a}\right)^{2}\right]-R\left(x_{t}^{a}\right)^{2}\right)=0$.

Differentiating both sides by dividends, we have $\alpha_{2}=0$ if $\frac{\partial E\left[x_{t+1}^{a}\right]}{\partial d_{t}}=0$. It follows that

$$
E\left[x_{t+1}^{a}\right]+\alpha_{1}\left(E\left[x_{t+1}^{a}\right]-R x_{t}^{a}\right)+\alpha_{3}\left(E\left[\left(x_{t+1}^{a}\right)^{2}\right]-R\left(x_{t}^{a}\right)^{2}\right)=0 .
$$

When earnings components aggregate in valuation they are expected to trade-off against each other dollar-for-dollar at the margin, $\partial E\left[x_{1 t+1}\right] / \partial E\left[x_{2 t+1}\right]=$ 
-1 . This implies that the parameters of the information dynamics governing the two earnings components are complementary (Pope and Wang 2005).

I summarize the above result in the following proposition.

Proposition 1: Assume A1, A2, A3, and dividend displacement on earnings. Valuation relevance of an earnings component is equivalent to forecasting relevance of the earnings component.

When dividend displacement on earnings is violated, or there exists some period $\tau$, such that $\partial E_{\tau}\left[x_{\tau+1}^{a}\right] / \partial d_{\tau} \neq 0$, then VI-1 does not imply FI-1. In this case, the relevance of earnings component $x_{2 t}$ in forecasting of abnormal earnings will depend on the dividend policy. If $x_{2 t}$ affects future period dividends or dividend policy, then it will be forecasting relevant even if it is valuation irrelevant.

\subsection{Dirty surplus earnings components}

When a valuation irrelevant earnings component is netted off against divi-

dends (VI-2), then the general valuation formula under A1, A2 and A3 can be written as

$$
P_{t}=b_{t}+G\left(x_{1 t}^{a}, b_{t}+d_{t}-x_{2 t}\right)
$$

where $x_{1 t}^{a}=x_{1 t}-(R-1) b_{t-1}$ is the 'core' abnormal earnings. Similar to the aggregation case, from A1 and equation (7), we know that the implied abnormal earnings dynamics must be consistent with valuation irrelevance VI-2 as below:

$$
E_{\tau}\left[x_{\tau+1}^{a}\right]+E_{\tau}\left[G\left(x_{1 \tau+1}^{a}, R b_{\tau}+x_{1 \tau+1}^{a}\right)\right]=R G\left(x_{1 \tau}^{a}, b_{\tau}+d_{\tau}-x_{2 \tau}\right) .
$$

Again I first discuss the impact of dividends on the core abnormal earn- 
ings dynamics, since an earnings component may be forecasting relevant for future core abnormal earnings via dividend policy. I then analyze the relation between future core abnormal earnings and the earnings component, i.e. $\partial E\left[x_{1 \tau}^{a} \mid I_{2 t}\right] / \partial x_{2 t}$ for any $\tau>t$. For the tractability of my analysis, I assume that any higher moments of core abnormal earnings are independent of any accounting variables.

When dividend displacement on earnings holds and dividends have no effect on the dynamics of the 'dirty surplus' earnings component, i.e., $\partial E_{\tau}\left[x_{2 \tau+1}\right] / \partial d_{\tau}$ $=0$ for any $\tau$, similar to aggregation case, equation (8) implies

$$
\begin{aligned}
& E_{\tau}\left[x_{\tau+1}^{a}\right]+G_{1}^{\prime}(0,0)\left(E_{\tau}\left[x_{1 \tau+1}^{a}\right]-R x_{1 \tau}^{a}\right) \\
& +\frac{1}{2} G_{1}^{\prime \prime}(0,0)\left(\left(E_{\tau}\left[x_{1 \tau+1}^{a}\right]\right)^{2}+\operatorname{var}\left(x_{1 t+1}^{a}\right)-R\left(x_{1 \tau}^{a}\right)^{2}\right)+\ldots \\
= & 0 .
\end{aligned}
$$

where $\operatorname{var}\left(x_{1 t+1}^{a}\right)$ is the variance of $x_{1 t+1}^{a}$. It is obvious that when $x_{2 \tau+1}$ is unpredictable, i.e. $E_{\tau}\left[x_{2 \tau+1}\right]=0, E_{\tau}\left[x_{\tau+1}^{a}\right]=E_{\tau}\left[x_{1 \tau+1}^{a}\right]$ can be expressed as a (nonlinear) function of $x_{1 t}^{a}$ by recursion. Consequently, $x_{2 t}$ is forecasting irrelevant for all future period expected (core) abnormal earnings. In general, we can show that, for any $\tau>t$,

$$
\begin{aligned}
\frac{\partial E\left[x_{\tau}^{a} \mid I_{2 t}\right]}{\partial x_{2 t}} & =\frac{E_{\tau}\left[G_{1}^{\prime}\right]}{1+E_{\tau}\left[G_{1}^{\prime}\right]} \frac{\partial E\left[x_{2 \tau} \mid I_{2 t}\right]}{\partial x_{2 t}}, \\
\frac{\partial E\left[x_{1 \tau}^{a} \mid I_{2 t}\right]}{\partial x_{2 t}} & =\frac{-1}{1+E_{\tau}\left[G_{1}^{\prime}\right]} \frac{\partial E\left[x_{2 \tau} \mid I_{2 t}\right]}{\partial x_{2 t}} .
\end{aligned}
$$

See the appendix for the proof. Therefore, when $x_{2 t}$ is VI-2 and dividend displacement on earnings holds, the dynamics of the component $x_{2 \tau}(\tau>t)$ will be the key for the relevance of $x_{2 t}$ in forecasting (core) abnormal earnings. Given $\partial E_{t}\left[x_{2 \tau}\right] / \partial d_{t}=0$, the earnings component $x_{2 t}$ will not be relevant for 
forecasting next period (core) abnormal earnings if it has no predicting role for itself, $\partial E\left[x_{2 \tau} \mid I_{2 t}\right] / \partial x_{2 t}=0$ for any $\tau>t$. On the other hand, if the earnings component is useful in predicting itself, i.e. $\partial E\left[x_{2 \tau} \mid I_{2 t}\right] / \partial x_{2 t} \neq 0$ for some $\tau$ then it will be forecasting relevant for abnormal earnings.

It is also clear that under VI-2, unpredictability of $x_{2 t+1}$ is a sufficient but not necessary condition for forecasting irrelevance of $x_{2 t}$. For instance, if $E_{t}\left[x_{2 t+1}\right]$ can be expressed in terms of $x_{1 t}^{a}$, then $x_{2 t}$ is FI-2 forecasting irrelevant. In other words, in contrast to Ohlson (1999), the irrelevance of earnings component $x_{2 t}$ in forecasting future expected abnormal earnings and valuation does not necessarily imply that $E_{t}\left[x_{2 t+1}\right]$ is unpredictable.

Similar to the aggregation case, I consider the following quadratic model as an example:

$G\left(x_{1 t}^{a}, b_{t}+d_{t}-x_{2 t}\right)=\alpha_{1} x_{1 t}^{a}+\alpha_{2}\left(b_{t}+d_{t}-x_{2 t}\right)+\alpha_{3}\left(x_{1 t}^{a}\right)^{2}=\left(\alpha_{1}+\alpha_{2}+\alpha_{3} x_{1 t}^{a}\right) x_{1 t}^{a}+\alpha_{2} R b_{t-1}$, where $\alpha_{1}$ and $\alpha_{3} \geq 0$. In this valuation model, the persistence of core abnormal earnings increases in current core abnormal earnings. Pope and Wang (2005) is a case with $\alpha_{3}=0$, while Ohlson (1999) is a special case with $\alpha_{2}=\alpha_{3}=0$. The no-arbitrage condition and the clean surplus accounting together imply the following abnormal earnings dynamic:

$E\left[x_{t+1}^{a}\right]+\left(\alpha_{1}+\alpha_{2}\right)\left(E\left[x_{1 t+1}^{a}\right]-R x_{1 t}^{a}\right)+\alpha_{3}\left(E\left[\left(x_{1 t+1}^{a}\right)^{2}\right]-R\left(x_{1 t}^{a}\right)^{2}\right)+\alpha_{2} R\left(b_{t}-R b_{t-1}\right)=0$.

Differentiating both sides by dividends, we have $\alpha_{2}=0$ if $\frac{\partial E\left[x_{t+1}^{a}\right]}{\partial d_{t}}=0$ and $\frac{\partial E\left[x_{2 t+1}\right]}{\partial d_{t}}=0$. It follows that

$$
E\left[x_{t+1}^{a}\right]+\alpha_{1}\left(E\left[x_{1 t+1}^{a}\right]-R x_{1 t}^{a}\right)+\alpha_{3}\left(E\left[\left(x_{1 t+1}^{a}\right)^{2}\right]-R\left(x_{1 t}^{a}\right)^{2}\right)=0 .
$$

When an earnings component is netted off with dividends in valuation, the two earnings components are substitutes. If $\frac{\partial v a r\left(x_{1 t+1}^{a}\right)}{\partial E\left[x_{2 t+1}\right]}=0$, we have 
$\frac{\partial E\left[x_{1 t+1}\right]}{\partial E\left[x_{2 t+1}\right]}=\frac{-1}{\left(1+\alpha_{1}+2 \alpha_{3} E\left[x_{1 t+1}^{a}\right]\right)}$. It is clear that there is not a dollar-for-dollar trade-off between two earnings components, nor $\left(1+\alpha_{1}\right)$ dollars of $x_{2 t+1}$ trades off against one dollar of $x_{1 t+1}$ as argued in Pope and Wang (2005) unless $\alpha_{3}=0$. In this simple nonlinear setup, the trade-off between two earnings components increases in future core abnormal earnings.

I summarize this result in the following proposition.

Proposition 2: Assume A1, A2, A3, dividend displacement on earnings, and dividends have no effect on the dynamics of an earnings component. VI-2 of the earnings component implies FI-2 if it has no role in predicting itself.

However, when dividend displacement on earnings is violated, or the dynamics of an earnings component depends on dividends, $\partial E_{t}\left[x_{2 t+1}\right] / \partial d_{t} \neq 0$, and earnings component $x_{2 t}$ affects future dividends or dividend policy such that $\partial E\left[d_{t+1} \mid I_{2 t}\right] / \partial x_{2 t} \neq 0$, then $x_{2 t}$ may be forecasting relevant for (core) abnormal earnings even if it is valuation irrelevant, i.e., VI-2 does not imply FI- $2 .{ }^{9}$

When a valuation irrelevant earnings component is combined with the lagged book value or apparently disappears from valuation (VI-3), the analysis is similar to the above discussion for VI-2. The details can be found in the appendix.

Proposition 3: Assume A1, A2, A3, dividend displacement on earnings, and dividends have no effect on the dynamics of an earnings component. VI-

\footnotetext{
${ }^{9}$ Note that discussion in Ohlson (1999) is based on information set $I_{0}$, which means $\partial P_{t} / \partial x_{2 t}=\partial b_{t} / \partial x_{2 t}=1$, i.e., a dollar of earnings components adds a dollar of both market value and book value. The notion that an earnings component has no effect on next period expected earnings if and only if it is passed on as dividends holds in our information set $I_{2}$ and VI-2 form valuation irrelevance with $\partial P_{t} / \partial x_{2 t}=\partial b_{t} / \partial x_{2 t}=0$.
} 
3 of the earnings component implies FI-3 if it is not relevant in forecasting itself.

\section{Discussion and Conclusion}

The analysis of informational relevance of earnings components in valuation and forecasting in Ohlson (1999) and Pope and Wang (2005) can be extended to non-transitory earnings and a nonlinear framework to incorporate gains/losses. Suppose that aggregate (core) abnormal earnings at time $t+1$ is associated with aggregate (core) abnormal earnings at time $t$ via a nonlinear function and in a Markovian system. Then the RIVM will lead to a nonlinear relation between value of equity and aggregate (core) abnormal earnings at time $t$. The nonlinearity of abnormal earnings and value of equity may be characterized as option valuation components as documented in the prior literature (Burgstahler and Dichev 1997; Yee 2000, 2005; Zhang 2000; Biddle et al. 2001). Although a forecasting irrelevant earnings component is also valuation irrelevant in corresponding type, i.e., FI- $j$ implies VI $j(j=1,2,3)$, Propositions 1-3 show that the converse is not generally true. I investigate this issue by firstly considering conditions for dividend displacement, and secondly the predictability of an earnings component for itself.

Studies concerned with testing a null hypothesis of irrelevance of earnings components may be informed by the analysis. I show that care is required in defining valuation relevance so as to ensure that coefficient values predicted under the null hypothesis reflect the reduced form relationships. Valuation irrelevance of an earnings component does not imply that the component 
should necessarily have a zero valuation weight in an unrestricted regression of market value on financial statement variables. One needs to define information irrelevance and the fundamental valuation relevant variables maintained to be sufficient for valuation in order to test the incremental valuation relevance of an earnings component by focusing on the parameter restrictions associated with an irrelevance definition. The analysis also shows that a one-to-one mapping between valuation relevance and forecasting relevance should not be expected. One cannot infer valuation relevance based on evidence of forecasting relevance. Nor can forecasting irrelevance be inferred from evidence of valuation irrelevance.

Finally, my model also appears to provide a basis for understanding some of the features of accounting practice. Although the analysis is presented in terms of two earnings components only, the intuition provides a rationale for the emergence of detailed line item disclosures in GAAP. At least at an anecdotal level, different line items subject to specific disclosure provisions under most GAAP regimes, such as depreciation, financing charges, and research and development expenses, 'other comprehensive income items', the gains/losses of financial derivatives qualified and not qualified for hedging, can be expected to have distinct information dynamics properties. GAAP/IFRS developments in relation to line item disclosures are usually not motivated by explicit consideration of the information dynamics. However, it is probable that at least some such disclosure requirements arise from an implicit belief that such items will be valued differently because they have different dynamic properties. 


\section{Appendix}

Proof of equation (4). Assume the relevant Leibniz integrals are well defined. Differentiate equation (3) with respect to $d_{\tau}$ and $x_{2 \tau}$ respectively, for any $\tau$, applying the chain rule, we have

$$
\begin{aligned}
\left(1+E_{\tau}\left[G_{1}^{\prime}\right]+E_{\tau}\left[G_{2}^{\prime}\right]\right) \frac{\partial E_{\tau}\left[x_{\tau+1}^{a}\right]}{\partial d_{\tau}} & =R E_{\tau}\left[G_{2}^{\prime}\right] \\
\left(1+E_{\tau}\left[G_{1}^{\prime}\right]+E_{\tau}\left[G_{2}^{\prime}\right]\right) \frac{\partial E\left[x_{\tau+1}^{a} \mid I_{1 \tau}\right]}{\partial x_{2 \tau}} & =-R E_{\tau}\left[G_{2}^{\prime}\right] \frac{\partial b_{\tau}}{\partial x_{2 \tau}}
\end{aligned}
$$

where derivatives of $G_{1}^{\prime}$ and $G_{2}^{\prime}$ are functions of $\left\{x_{\tau+1}^{a}, b_{\tau+1}+d_{\tau+1}\right\}$.

When dividend displacement on earnings holds, $\frac{\partial E_{\tau}\left[x_{\tau+1}^{a}\right]}{\partial d_{\tau}}=0$, equation (11) implies that $E_{\tau}\left[G_{2}^{\prime}(.,).\right]=0$ for any accounting variables and any time period $\tau$, which further implies that $E\left[G_{2}^{(n)}(.,).\right]=0(n=1,2, \ldots)$. Equation (12) then implies $\partial E\left[x_{\tau+1}^{a} \mid I_{1 \tau}\right] / \partial x_{2 \tau}=0$. By recursion, equation (3) leads to $\frac{\partial E_{t}\left[x_{\tau}^{a}\right]}{\partial d_{t}}=0$ and $\frac{\partial E_{t}\left[x_{\tau}^{a} \mid I_{1 t}\right]}{\partial x_{2 t}}=0$ for any $\tau>t$.

Proof of equations (9) and (10). Differentiate equation (8) with respect to $x_{t}^{a}$, we have

$$
\frac{\partial E_{\tau}\left[x_{\tau+1}^{a}\right]}{\partial d_{\tau}}+\left(E_{\tau}\left[G_{1}^{\prime}\right]+E_{\tau}\left[G_{2}^{\prime}\right]\right) \frac{\partial E_{\tau}\left[x_{1 \tau+1}^{a}\right]}{\partial d_{\tau}}=R E_{\tau}\left[G_{2}^{\prime}\right]
$$

where $G_{1}^{\prime}$ is the partial derivative with respect to the first variable and $G_{2}^{\prime}$ is the partial derivative with respect to the second variable. Derivatives of $G_{1}$ and $G_{2}$ are functions of $\left\{x_{1 \tau+1}^{a}, b_{\tau+1}+d_{\tau+1}-x_{2 \tau+1}\right\}$. When dividend displacement on earnings holds and dividends have no role in predicting earnings component $x_{2 t}, \partial E\left[x_{2 \tau+1}\right] / \partial d_{\tau}=0$ for any $\tau$, then $\partial E\left[x_{1 \tau+1}^{a}\right] / \partial d_{\tau}=$ $\partial E\left[x_{\tau+1}^{a}\right] / \partial d_{\tau}-\partial E\left[x_{2 \tau+1}\right] / \partial d_{\tau}=0$. Equation (13) implies $E\left[G_{2}^{\prime}(.,).\right]=0$. Since this holds for arbitrary time $\tau$ and any accounting numbers, we have, 
$E\left[G_{2}^{(n)}(.,).\right]=0$ for $n=1,2, \ldots$ Differentiate equation (8) with respect to $x_{2}$, we further have

$$
\frac{\partial E\left[x_{t+1}^{a} \mid I_{2 t}\right]}{\partial x_{2 t}}+E_{t}\left[G_{1}^{\prime}\right] \frac{\partial\left[x_{1 t+1}^{a} \mid I_{2 t}\right]}{\partial x_{2 t}}=0
$$

By recursion, equation (8) implies $\frac{\partial E\left[x_{\tau}^{a} \mid I_{2 t}\right]}{\partial x_{2 t}}+E_{\tau}\left[G_{1}^{\prime}\right] \frac{\partial\left[x_{1 \tau}^{a} \mid I_{2 t}\right]}{\partial x_{2 t}}=0$ for any $\tau>t+1$. Equation (14) and $\frac{\partial E\left[x_{\tau}^{a} \mid I_{2 t}\right]}{\partial x_{2 t}}-\frac{\partial E\left[x_{2 \tau} \mid I_{2 t}\right]}{\partial x_{2 t}}=\frac{\partial\left[x_{1 \tau}^{a} \mid I_{2 t}\right]}{\partial x_{2 t}}$ further imply equations (9) and (10).

\section{Proof of Proposition 3.}

When a valuation irrelevant earnings component is combined with the lagged book value or apparently disappears from valuation (VI-3), then the general valuation formula under A1, A2 and A3 can be written as

$$
P_{t}=b_{t}+G\left(x_{1 t}^{a}, b_{t}+d_{t}\right)
$$

where $x_{1 t}^{a}=x_{1 t}-(R-1)\left(b_{t-1}+x_{2 t}\right)$. From A1 and equation (15), we know that the implied abnormal earnings dynamics must satisfy the information dynamics in consistent with respective valuation irrelevance VI-3 as below:

$$
E_{\tau}\left[x_{\tau+1}^{a}\right]+E\left[G\left(x_{1 \tau+1}^{a}, R b_{\tau}+x_{\tau+1}^{a}\right)\right]=R G\left(x_{1 \tau}^{a}, b_{\tau}+d_{\tau}\right)
$$

Differentiate equation (16) with respect to $d_{\tau}$, note that $x_{\tau}^{a}=x_{1 \tau}^{a}+R x_{2 \tau}$, we obtain

$$
\left(1+E_{\tau}\left[G_{2}^{\prime}\right]\right) \frac{\partial E_{\tau}\left[x_{\tau+1}^{a}\right]}{\partial d_{\tau}}+E_{\tau}\left[G_{1}^{\prime}\right]\left(\frac{\partial E_{\tau}\left[x_{\tau+1}^{a}\right]}{\partial d_{\tau}}-R \frac{\partial E_{\tau}\left[x_{2 \tau+1}\right]}{\partial d_{\tau}}\right)=R E_{\tau}\left[G_{2}^{\prime}\right]
$$

where $G_{1}^{\prime}$ is the partial derivative with respect to the first variable and $G_{2}^{\prime}$ is the partial derivative with respect to the second variable. When divi- 
dend displacement on earnings holds and $\partial E_{\tau}\left[x_{2 \tau+1}\right] / \partial d_{\tau}=0$, then equation (17) implies that $E\left[G_{2}^{\prime}\right]=0$ for each time period $\tau$. Given $G(0,0)=0$, $E_{\tau}\left[G_{2}^{(n)}(.,).\right]=0$ for $n=1,2, \ldots$ and equation (16), Taylor expansion gives:

$$
\begin{aligned}
& E_{t}\left[x_{t+1}^{a}\right]+G_{1}^{\prime}(0,0)\left(E_{t}\left[x_{1 t+1}^{a}\right]-R x_{1 t}^{a}\right) \\
& +\frac{1}{2} G_{1}^{\prime \prime}(0,0)\left(\left(E_{t}\left[x_{1 t+1}^{a}\right]\right)^{2}+\operatorname{var}\left(x_{1 t+1}^{a}\right)-R\left(x_{1 t}^{a}\right)^{2}\right)+\ldots \\
= & 0 .
\end{aligned}
$$

On the other hand, differentiate equation (16) with respect to $x_{2 t}$, by recursion, we obtain

$$
\frac{\partial E\left[x_{\tau}^{a} \mid I_{3 t}\right]}{\partial x_{2 t}}+E_{\tau}\left[G_{1}^{\prime}\right] \frac{\partial E\left[x_{1 \tau}^{a} \mid I_{3 t}\right]}{\partial x_{2 t}}=0
$$

Note that $\frac{\partial E\left[x_{\tau}^{a} \mid I_{3 t}\right]}{\partial x_{2 t}}-\frac{\partial E\left[x_{1 \tau}^{a} \mid I_{3 t}\right]}{\partial x_{2 t}}=R \frac{\partial E\left(x_{2 \tau} \mid I_{3 t}\right)}{\partial x_{2 t}}$. Equations (17) and (18) together imply that

$\frac{\partial E\left[x_{1 \tau}^{a} \mid I_{3 t}\right]}{\partial x_{2 t}}=-\frac{R}{1+E_{\tau}\left[G_{1}^{\prime}\right]} \frac{\partial E\left[x_{2 \tau} \mid I_{3 t}\right]}{\partial x_{2 t}}, \frac{\partial E\left[x_{\tau}^{a} \mid I_{3 t}\right]}{\partial x_{2 t}}=\frac{R E_{\tau}\left[G_{1}^{\prime}\right]}{1+E_{\tau}\left[G_{1}^{\prime}\right]} \frac{\partial E\left[x_{2 \tau} \mid I_{3 t}\right]}{\partial x_{2 t}}$.

Therefore, when $x_{2 t}$ is VI-3 and dividend displacement on earnings holds and dividends have no role in forecasting $x_{2 \tau}, \partial E_{\tau}\left[x_{2 \tau+1}\right] / \partial d_{\tau}=0$ for any $\tau$, then the earnings component will not be relevant for forecasting (core) abnormal earnings if it has no role for predicting itself, $\partial E\left[x_{2 \tau} \mid I_{3 t}\right] / \partial x_{2 t}=0$ for any $\tau$. On the other hand, if $\partial E\left[x_{2 \tau} \mid I_{3 t}\right] / \partial x_{2 t} \neq 0$ for some period $\tau$, then it will be forecasting relevant for abnormal earnings.

If dividend displacement on earnings does not hold or the dynamics of an earnings component is affected by dividends, or equivalently $\partial E_{t}\left[x_{t+1}^{a}\right] / \partial d_{t} \neq$ 0 or $\partial E_{t}\left[x_{1 t+1}^{a}\right] / \partial d_{t} \neq 0$, then the earnings component via dividend policy, such that $\partial E\left[d_{t+1} \mid I_{3 t}\right] / \partial x_{2 t} \neq 0$, may be forecasting relevant even if it is valuation irrelevant, i.e., VI-3 does not imply FI-3. In other words, a forecasting relevant earnings component may not be valuation relevant. 
Acknowledgments: I am indebted to Peter Pope for imparting his knowledge and insights. I also appreciate the many helpful comments received from Jim Ohlson, Ken Peasnell, Judson Caskey (discussant at the American Accounting Association annual conference) and participants at European Accounting Association Annual Congress and Imperial College London on earlier versions of the paper. 


\section{References}

Ashton D, Cooke T, Tippett M, Wang P (2004) Linear information dynamics, aggregation, dividends and dirty surplus accounting. Account Bus Res 34: $277-299$.

Bamber L, Jiang J, Petroni K, Wang I (2010) Comprehensive income: who's afraid of performance reporting. Account Rev 85:97-126.

Barth M, Beaver W, Landsman W (1998) Relative valuation roles of equity book value and net income as a function of financial health. J Account Econ 25:1-34.

Barth M, Beaver W, Hand J, Landsman W (1999) Accruals, cash flows, and equity values. Rev Account Stud 3:205-229.

Barth M, Beaver W, Hand J, Landsman W (2005) Accruals, accountingbased valuation models and the prediction of equity values. J Account Audit Finance 32:435-776.

Berger P, Ofek E, Swary I (1996) Investor valuation of the abandonments option. J Financ Econ 42:257-287.

Biddle G, Chen P, Zhang G (2001) When capital follows profitability: non-linear residual income dynamics. Rev Account Stud 6:229-265.

Burgstahler D, Dichev I (1997) Earnings, adaptation and equity value. Account Rev 72:187-215.

Callen JL, Morel M (2001) Linear accounting valuation when abnormal earnings are AR (2). Rev Quant Financ Acc 16:191-203

Chambers D, Linsmeier T, Shakespeare C, Sougiannis T (2007) An evaluation of SFAS No. 130 comprehensive income disclosures. Rev Account Stud 12:557-593. 
Dechow P, Hutton A, Sloan R (1999) An empirical assessment of the residual income valuation model. J Account Econ 26:1-34.

Dhaliwal D, Subramanyam K, Trezevant R (1999) Is comprehensive income superior to net income as a measure of firm performance. J Account Econ 26:43-67.

Dixit A, Pindyck R (1994) Investment under uncertainty. Princeton University Press.

Edwards E, Bell P (1961) The theory of and measurement of business income. University of California Press.

Feltham G, Ohlson J (1995) Valuation and clean surplus accounting for operating and financial activities. Contemp Account Res 11:689-732.

Feltham G, Ohlson J (1996) Uncertainty resolution and the theory of depreciation measurement. J Account Res 34:209-234.

Financial Accounting Standards Board (FASB) (2010) Accounting for financial instruments and revisions to the accounting for derivative instruments and hedging activities. Exposure draft. Stanford, CT.

Higgins H (2011) Forecasting stock price with the residual income model. Rev Quant Finan Acc 36:583-604

Lee CF, Lee J (2010) Handbook of quantitative finance and risk management, Springer.

Miller M, Modigliani F (1961) Dividend policy, growth and the valuation of shares. J Bus 34:411-433.

Ohlson J (1989) Accounting earnings, book value, and dividends: the theory of the clean surplus equation. in R.P. Brief and K.V. Peasnell, Clean surplus-a link between accounting and finance (1996), New York: Garland 
Publishing.

Ohlson J (1991) The theory of value and earnings, and an introduction to the Ball-Brown analysis. Contemp Account Res 8:1-19.

Ohlson J (1995) Earnings, book values, and dividends in security valuation. Contemp Account Res 11:661-687.

Ohlson J (1999) On transitory earnings. Rev Account Stud 3/4:145-162.

Ohlson J, Gao Z (2006) Earnings, earnings growth and value. Foundations and Trends in Accounting 1:1-70.

Ohlson J, Juettner-Nauroth B (2005) Expected EPS and EPS growth as determinants of value. Rev Account Stud 10:349-365.

Peasnell K (1982) Some formal connections between economic values and yields and accounting numbers. J Bus Financ Account 9:361-381.

Pope F, Wang P (2005) Earnings components, accounting bias and equity valuation. Rev Account Stud 10:387-407.

Schipper K (2007) Required disclosure in financial reports. Account Rev 82:301-326.

Stark A (1997) Linear information dynamics, dividend irrelevance, corporate valuation and the clean surplus relationship. Account Bus Res 27:219228.

Subramanyam K, Wild J (1993) The going concern assumption and the informativeness of earnings. Contemp Account Res 13:251-273.

Tsay RS, Lin Y, Wang H (2008) Residual income, value-relevant information and equity valuation: a simultaneous equations approach. Rev Quant Financ Acc 31:331-358.

Yee K (2005) Aggregation, dividend irrelevancy, and earnings-value rela- 
tions. Contemp Account Res 22:453-80.

Yee K (2000) Opportunities knocking: residual income valuation of an adaptive firm. J Account Audit Finance 15:225-266.

Zhang G (2000) Accounting information, capital investment decisions, and equity valuation: theory and empirical implications. J Account Res 38:271-295. 